\title{
Illness Perception Ratings of High-Risk Newborns by Mothers and Clinicians: Relationship to Illness Severity and Maternal Stress
}

\author{
Stacey Brooks \\ University of Auckland
}

\author{
Simon Rowley \\ Auckland City Hospital, New Zealand
}

\author{
Elizabeth Broadbent and Keith J. Petrie \\ University of Auckland
}

\begin{abstract}
Objective: Patients' views of illness are often thought to differ from those of medical staff, although this is rarely assessed. This study examined the correspondence between mothers' and clinicians' perceptions of the same high-risk newborns, as well as with an objective measure of illness severity. We also investigated how mothers' perceptions were related to reported stress. Methods: Mothers of 99 high-risk infants admitted to either a neonatal intensive care or neonatal high dependency unit, which offers specialized but not intensive care, completed illness perception ratings of their baby's condition as well as perceived stress 3 to 5 days following admission. At the same time, a standardized measure of neonatal illness severity was calculated and the baby's primary neonatologist completed illness perceptions ratings. Results: Unlike clinician ratings, mothers' illness perceptions were not significantly correlated with illness severity. Mothers generally rated babies in both units as sicker and having a more serious illness than did neonatologists. Whereas clinicians, compared with mothers, rated babies in intensive care as having an illness that would affect their life more and last for a longer time. Mothers rated medical treatment to be significantly more helpful than did clinicians, particularly for babies admitted to the high dependency unit. Mothers' stress was significantly associated with illness perceptions but unrelated to illness severity. Conclusions: Significant differences exist in the perceptions of illness severity, helpfulness of treatment, and the long-term effects of the baby's illness between parents and clinicians and this may lead to misunderstandings and misinterpretations in communication.
\end{abstract}

Keywords: illness perceptions, stress, medical staff, mothers, pediatrics, intensive care

The admission of a newborn to intensive care is often an unexpected event and can spoil parents' expectations of delivering a healthy baby. While improved technology and training mean that even very low weight and premature babies admitted to special care baby units now have a very good chance of survival, parents often face an anxious time during their infant's hospital stay. Previous studies show parental stress during this time to be high, with parents having to deal with uncertainties over their baby's condition, as well as facing the unfamiliar environment of a special care or intensive care baby unit (Redshaw, 1997; Shaw et al., 2006; Thompson, Oehler, Catlett, \& Johndrow, 1993). These units are known by different names, but essentially, intensive care units (also called neonatal intensive care units or NICUs) care for extremely low birth weight and premature infants, those requiring assisted ventilation, and infants with complex and critical health

This article was published Online First March 5, 2012

Stacey Brooks, Department of Psychological Medicine, University of Auckland, Auckland, New Zealand; Simon Rowley, Newborn Services, Auckland City Hospital, New Zealand; Elizabeth Broadbent and Keith J. Petrie, Department of Psychological Medicine, University of Auckland.

Correspondence concerning this article should be addressed to Keith J. Petrie, Psychological Medicine, Faculty of Medical and Health Sciences, University of Auckland, Private Bag 92019, Auckland, New Zealand. E-mail: kj.petrie@auckland.ac.nz conditions. High dependency units (also called special care baby units or SCBU) normally care for infants who do not require assisted ventilation or complicated intravenous feeding regimens and who are usually more mature. They are also used for transitioning babies from intensive care before discharge from hospital.

While previous research looking at the relationship between parental and clinician perceptions of high-risk newborns has been limited by retrospective data, there is a strong suggestion in the literature that parental perceptions of the severity of babies admitted to intensive care and high dependency units may not correspond well with objective clinical markers of severity (Affleck, Tennen \& Rowe, 1990; Catlett, Miles \& Holditch-Davis, 1994). If so, this has important clinical implications, as medical staff may not realize that parents do not share a similar view of the infant's illness and this can lead to misunderstandings in communication. Parental and clinician differences in perceptions about the severity of the infant's illness may make it difficult for parents to accept specific treatment interventions when they do not fit with parental beliefs of severity.

Early work on patients' perceptions of illness has provided a theoretical model for understanding patient behavior when faced with an illness threat (Leventhal, Nerenz, \& Steele, 1984), and this work has been recently applied more widely to caregivers and family members (Broadbent, Ellis, Thomas, Gamble \& Petrie, 2009a; Weinman, Petrie, Sharpe, \& Walker, 2000). Illness percep- 
tions provide a framework for patients or caregivers to make sense of their medical condition and to guide behavior directed at managing the illness. Illness perceptions are comprised of a number of interrelated beliefs about the cause of the illness, how long it will last, what the consequences of the illness are on the patient's life, the symptoms that go with the condition and how the illness is controlled or cured (Petrie \& Weinman, 2006). A number of studies have now shown patients' perceptions of their illness vary widely, even between patients with similar illnesses or injuries, and are associated with a range of important health outcomes including return to work, later disability, depression, and higher subsequent health care expenditure (e.g., Broadbent, Petrie, Ellis, Ying \& Gamble, 2004; Dickens et al., 2008; Foster et al., 2008; Frostholm et al., 2005; Frostholm et al., 2007; Petrie, Weinman, Sharpe, \& Buckley, 1996).

Leventhal's common sense model also proposes that the cognitive representation of the patient's illness produces a parallel emotional response in reaction to the perceived degree of threat (Leventhal \& Diefenbach, 1991). In the case of parents of highrisk newborns, parental perceptions about the severity of the baby's illness are likely to strongly influence the level of stress parents are experiencing during the hospital admission, with more negative perceptions of illness being associated with higher levels of stress. If parental perceptions about the baby's illness do not fit well with clinician views then neonatal staff may not be aware of the level of distress of many parents of infants with objectively less severe illness.

While there is little research involving high-risk neonatal groups, previous work looking at pediatrician and parental views of older childrens' illness suggest that there are often differences between parents and doctors in their perceptions of the seriousness of the condition and how the illness affects the child. A recent study comparing parental perceptions of the urgency of their child's illness with emergency physicians' ratings found significant discrepancies between the perceptions of parents and doctors (Kalidindi, Mahajan, Thomas, \& Sethuraman, 2010). While $94 \%$ of parents considered their child's illness as needing urgent care, only $31 \%$ of these children were classified as needing urgent care by clinicians. Previous research also suggests that pediatricians and parents often have different perceptions of the effect of an illness on a child's quality of life and level of pain (Janse, Sinnema, Uiterwaal, Kimpen, \& Gemke, 2008; Morrow, Hayden, Quine, Scheinberg, \& Craig, 2012).

The current study had three aims. The first was to investigate the relationship between mothers' perceptions of their high-risk baby's illness and objective measures of illness severity. Based on previous work, it was predicted that while clinician ratings would be related to illness severity, mothers' perceptions would not be significantly associated with objective indices of severity. With the second aim, the study investigated how mothers' and clinicians' illness perceptions differed for babies admitted to high dependency and intensive care units. Because it was anticipated that clinicians' perceptions would be more closely related to illness severity, we predicted that clinicians and mothers would show more divergence in their perceptions for babies admitted to intensive care units, with clinicians rating their illnesses as more serious. And finally, the third aim examined the relationship between mothers' illness perceptions and their level of reported stress. Based on Leventhal's common sense model, we predicted that more severe illness per- ception ratings would be associated with higher levels of stress but not with measures of illness severity.

\section{Method}

\section{Participants}

A sample of mothers of consecutive infants admitted to the high dependency or intensive care units and their respective clinicians were recruited from Auckland City Hospital Newborn Service. Mothers were excluded from the study if their infant was receiving terminal care or the infant was born at less than 23 weeks gestation.

During the 5 months of the study, 190 infants were admitted to the service. Of this number, 35 mothers were unable to be contacted or seen by the research assistant within 5 days of admission. Nine further mothers were excluded because of the medical condition of the baby. Forty-four mothers declined to participate, with 10 stating they were too busy to take part, nine because they were about to be transferred or discharged, and 25 giving another or no reason. Three other babies had ratings completed by someone other than their mother and so were also excluded.

The total sample therefore was comprised of the mothers and clinicians of 99 infants; 62 infants admitted to the high dependency unit and 37 infants admitted to the intensive care unit. There were 7 cases of twins in the sample, and for consistency in these cases, mothers were asked to complete the questionnaire based on their second twin. The mothers average age was 31.5 years $(S D=6.7)$. In terms of level of formal education, $3 \%$ had only primary school education, $34 \%$ secondary schooling, $24 \%$ a postsecondary school diploma or trade certificate, and 39\% held a University degree. The majority of mothers were European (59\%), with the remainder Pacific Islanders (14\%), Maori (11\%), or from other ethnic groups. Most mothers were in married or de facto relationships (81\%). The majority of mothers were employed full-time (47\%), with $7 \%$ employed part-time and $16 \%$ working from home. Of the remainder, $19 \%$ described themselves as unemployed, $4 \%$ as students, and the remainder was receiving a government income support benefit. Forty-six percent of the sample had no previous children, $33 \%$ had one child, $13 \%$ two children, and $8 \%$ three or more.

The primary neonatologist responsible for the infant also completed ratings. At the time of the study, five consultant neonatologists were caring for infants in both the high dependency and intensive care units in the largest New Zealand University teaching hospital. The Auckland City Hospital Newborn service is one of two intensive care units in the region and is the largest in New Zealand, with 16 intensive care and 30 high dependency cots. The hospital has approximately 7,500 inborn deliveries and provides intensive care for a further 10,000 regional deliveries. In addition, it provides quaternary services for cardiac, general surgery and otorhinolaryngology for the whole region. There are normally six neonatologists providing supervision of high dependency and intensive care units. There are approximately 900 admissions per year with 160 infants less than $1,500 \mathrm{~g}$ birth weight.

\section{Procedure and Measures}

The Ministry of Health Northern X Committee and the Auckland District Health Board Research Review Committee approved 
the study. Written consent was obtained from all participants. Mothers of infants who were admitted to either the high dependency or intensive care units were approached and informed about the study. Mothers and the relevant neonatologist independently completed research questionnaires between Day 3 to 5 after the infant's admission to the unit.

Both mothers and neonatologists completed a modified version of the Brief Illness Perception Questionnaire (Broadbent, Petrie, Main, \& Weinman, 2006) to assess perceptions of the infant's condition. This is a brief 9-item measure that encompasses the main dimensions of illness perceptions. Normally, the scale is completed by a patient with respect to his or her own illness. However, in this study the scale was modified to obtain the parental and clinician perceptions of the infant's condition (Table 1). For example, the item "How much does your illness affect your life?" was altered for mothers to "How much will your baby's illness or condition affect his or her life?" For the clinician version the words "your baby's" was replaced by "the baby's". All items were rated on an 11-point scale (0 to 10) with relevant anchors. Since its publication, the Brief Illness Perception Questionnaire has been used in a series of studies in a variety of illnesses (e.g., Broadbent et al., 2009b; Chong, Mackey, Broadbent, Stott, in press; Foster et al., 2008; Petrie, Perry, Broadbent, \& Weinman, 2011; Stack et al., 2011) and ethnic groups, including Maori and Pacific Islander populations (Bean, Cundy \& Petrie, 2007; Sanders, Kydd, Morunga, \& Broadbent, 2011). The scale has good test-retest reliability and has been associated with a variety of outcomes in chronic illness in adults such as metabolic control in diabetes, asthma morbidity and a slower recovery from myocardial infarction (Broadbent et al., 2006). The scale has also been associated with a slower return to work following illness (Giri, Poole, Nightingale \& Robertson, 2009) and help-seeking for migraine headaches (Lantéri-Minet et al., 2007).

Mothers also completed the 10-item version of the Perceived Stress Scale (Cohen, Kamarck \& Mermelstein, 1983), which was used to assess the degree to which mothers appraised their life as stressful since the birth of their child. The scale assesses the extent to which individuals perceive their life to be unpredictable, uncontrollable and overloading, which are considered to be the central characteristics of perceived stress. Examples of items are: "In the past week, how often have you felt nervous and stressed?" and "In the past week how often have you felt that you were unable to control the important things in your life?" Responses to items are rated from "never" (0) to "very often" (3). The scale is widely used and has good psychometric properties (Cole, 1999; Mitchell, Crane, \& Kim, 2008). The Perceived Stress Scale has also been used in previous work with parents of preterm infants and has also been found to be a reliable and valid measure in this population (Hobel, 2004).

After training from a senior pediatrician, the research assistant, a postgraduate health psychology student, extracted data from the clinical records to establish the Clinical Risk Index for Babies score (CRIB-II; Parry, Tucker, Tamow-Mordi, \& U.K. Neonatal Staffing Study Collaborative Group, 2003). The CRIB-II is an objective measure of illness severity and is based on an algorithm using the following clinical data to predict likelihood of mortality in neonates: gender, birth weight, gestation, congenital malformations, temperature at admission, maximum base excess (acidity of the infant's blood) in the first $12 \mathrm{hr}$ and overall maximum base excess, as well as the minimum and maximum appropriate fraction of inspired oxygen in the first $12 \mathrm{hr}$ needed to keep a normal arterial oxygen saturation. Higher scores on the CRIB-II indicate greater illness severity and the scale has demonstrated good validity in neonatal units as a measure of illness severity (Gagliardi et al., 2004).

\section{Data Analysis}

We calculated that a sample of at least 85 participants would be required to detect a moderate level of agreement $(r=.30)$ between mothers' perceived severity of the babies' illness and actual severity based on previous work (Broadbent, Petrie, Ellis et al., 2006), using power of .80 and a $p$ value of .05 . The normality of data was checked using Kolmogorov-Smirnov. Mann-Whitney U and chi-square analyses were performed to analyze differences between babies admitted to the high dependency and intensive care units on demographic and medical characteristics. Spearman's rho correlations were used to test the associations between illness perceptions and the babies' birth weight, gestation, and CRIB-II scores, as well as mothers' stress levels. To investigate differences between mothers' and clinicians' perceptions, mixed analysis of variance (ANOVA) were conducted for each illness perception; the repeated measures variable was the mother's and doctor's perceptions of the baby, and the between subject variable was whether the baby was in the high dependency or intensive care unit. For the three illness perceptions not asked of clinicians,

Table 1

Brief Illness Perception Questionnaire Items

Item

Anchors (0-10)

How much will your/the baby's illness or condition affect his or her life? How long do you think your/the baby's illness will continue?

How much control do you feel you have over your baby's illness?*

How much do you think your/the baby's treatment can help his/her illness?

How sick is your/the baby?

How concerned are you about your/the baby's illness?

How well do you feel you understand your baby's illness?*

How much does your baby's illness affect you emotionally?*

How much do you think your/the baby's condition is a serious condition?
No effect to severely affect his/her life

A very short time to forever

Absolutely no control to extreme amount of control

Not at all helpful to extremely helpful

Not sick at all to extremely sick

Not at all concerned to extremely concerned

Don't understand at all to understand very clearly

Not at all affected emotionally to extremely affected emotionally Not serious to extremely serious

\footnotetext{
* Items only asked of parents not neonatologists.
} 
mothers of babies in the intensive care unit were compared with mothers of babies in high dependency unit using Mann-Whitney $U$ tests. A one-sample $t$ test compared the stress levels of mothers to population norms, and an independent samples $t$ test compared stress levels of mothers between the high dependency and intensive care groups.

\section{Results}

The characteristics of the infants admitted to high dependency and intensive care units are shown in Table 2. As would be expected, infants admitted to the intensive care unit weighed less, had an earlier gestation, more congenital problems and a significantly higher CRIB-II score than infants admitted to the high dependency unit.

\section{Illness Perceptions}

The first hypothesis that the clinicians' ratings would be related to objective measures of illness severity while mothers' ratings would not was tested by examining the correlations between illness perceptions and the objective measures of birth weight, gestation, and CRIB-II score (Table 3). As can be seen from the table, mothers' perceptions of their baby's illness are largely unrelated to objective indices of severity. For clinicians, perceptions of illness are strongly associated with the baby's CRIB-II score (all correlations statistically significant) and, to a lesser degree, gestation (four of six significant) and birth weight (one of six significant). The overall pattern of results supports the prediction that, unlike clinician ratings, parental perceptions are unrelated to objective measures of illness severity.

The illness perception ratings of mothers of high dependency and intensive care babies were compared with the ratings of clinicians to test the prediction that there would be significant differences between the clinicians and parents in their views of the baby's condition and these differences would be greater in the intensive care unit. The differences are illustrated in Figure 1, and Table 4 presents the test statistics.

Overall, the results confirm the prediction that mothers and clinicians hold significantly different perceptions of illness for the same baby and a greater number of perceptions differ in the intensive care unit. In the intensive care unit, clinicians perceived the illness would affect the babies' lives more than their mothers did. The clinicians thought that the illness would last longer, and that treatment would be less helpful than the babies' mothers did. There was no difference in how sick the mothers and clinicians saw the babies. Mothers were more concerned than clinicians about their babies and saw the babies' condition as more serious. In the high dependency unit, mothers and clinicians had similar perceptions about how much the babies' lives would be affected, and how long the illness would last. Mothers thought that treatment would be much more helpful than did clinicians. Mothers also saw their babies as sicker, were more concerned about their babies, and thought the babies' condition was more serious, than clinicians.

For three illness perceptions (personal control, understanding, and emotional representation), only mothers' perceptions were assessed. There were no statistically significant differences between mothers with babies in the high dependency unit and mothers with babies in the intensive care unit in how much personal control they felt over their baby's illness, how well they understood the illness, or how much they were emotionally affected by their baby's illness (all $p \mathrm{~s}>.05$ ).

\section{Stress}

The overall level of stress in mothers of the infants admitted to high dependency and intensive care units was high. Compared with population means for the Perceived Stress Scale $(M=13.02$, $S D=6.35$, Cohen $\&$ Williamson, 1988) mothers reported significantly higher levels of stress $(M=19.50, S D=7.38) t(98)=$ $8.73, p=.001$. There was no significant difference in the level of stress in mothers of infants admitted to the high dependency unit $(M=19.15, S D=6.48)$ compared with mothers of intensive care unit infants $(M=20.10, S D=8.75 ; t(60)=-.56, p=.58)$.

The relationship between parental stress level and illness severity was examined, as well as how stress related to mothers' illness perceptions. As can be seen in Table 5, there was no significant relationship between mothers' overall level of perceived stress and the baby's CRIB-II measure of illness severity. Mothers' stress levels did not correlate significantly with gestation period but were significantly correlated with birth weight. However, the direction of this correlation is in a positive direction (high birth weight

Table 2

Summary of Birth Characteristics in High Dependency and Intensive Care Unit Babies

\begin{tabular}{|c|c|c|c|}
\hline Characteristic & High dependency $(n=62)$ & Intensive care $(n=37)$ & Significance \\
\hline \multicolumn{4}{|l|}{ Gender } \\
\hline Male & $33(53)$ & $26(70)$ & \multirow[t]{2}{*}{$\chi^{2}(1, N=99)=2.80, p=.14$} \\
\hline Female & $29(47)$ & $11(30)$ & \\
\hline \multicolumn{4}{|l|}{ Birth weight (grams) } \\
\hline$M(S D)$ & $2,225.48(662.69)$ & $1,758.29(1,072.80)$ & \multirow{3}{*}{$\begin{array}{l}z=-3.62, p=.001 \\
\chi^{2}(1, N=99)=19.34, p=.001\end{array}$} \\
\hline$\leq 1,500 \mathrm{~g}$ & $8(13)$ & $20(54)$ & \\
\hline$<1,501 \mathrm{~g}$ & $54(87)$ & $17(46)$ & \\
\hline Gestation weeks $M(S D)$ & $34.05(2.22)$ & $31.43(4.89)$ & $Z=-3.42, p=.001$ \\
\hline \multicolumn{4}{|l|}{ Congenital malformation } \\
\hline None & $56(90)$ & $25(71)$ & \multirow[t]{2}{*}{$\chi^{2}(1, N=97)=5.80, p=.02$} \\
\hline One or more & $6(10)$ & $10(29)$ & \\
\hline CRIB-II score, $M(S D)$ & $1.92(1.15)$ & $6.35(4.28)$ & $z=-5.27, p=.001$ \\
\hline
\end{tabular}

Note. $\quad$ CRIB-II = Clinical Risk Index for Babies score. Except where indicated, values show number of participants (with percentages in parentheses). 
Table 3

Correlations Between Illness Perceptions and Illness Severity (CRIB-II), Birth Weight, and Gestation for Mothers and Clinicians

\begin{tabular}{|c|c|c|c|c|c|c|}
\hline \multirow{2}{*}{$\begin{array}{l}\text { Illness perception } \\
\text { item }\end{array}$} & \multicolumn{3}{|c|}{ Mothers } & \multicolumn{3}{|c|}{ Clinicians } \\
\hline & Birth weight & Gestation & CRIB-II & Birthweight & Gestation & CRIB-II \\
\hline Illness affect life & -.02 & -.02 & .15 & $-.28^{* *}$ & $-.27^{* * *}$ & $.39^{* *}$ \\
\hline Length illness last & -.18 & -.13 & $.24^{*}$ & -.20 & $-.25^{*}$ & $.34^{* *}$ \\
\hline Control over illness & .06 & .01 & -.09 & - & - & - \\
\hline Treatment can help & -.07 & -.07 & .05 & -.15 & $-.25^{*}$ & $.33^{* *}$ \\
\hline How sick is baby & .08 & .11 & .09 & -.17 & $-.24^{*}$ & $.35^{* *}$ \\
\hline How concerned & .01 & .11 & .08 & -.11 & -.12 & $.34^{* *}$ \\
\hline Understand & -.18 & -.07 & .06 & - & - & - \\
\hline Affect emotionally & .15 & .19 & -.00 & - & - & - \\
\hline Serious condition & -.03 & .06 & .12 & -.07 & -.09 & $.25^{*}$ \\
\hline
\end{tabular}

${ }^{*} p<.05 . \quad * * 0<.01$

associated with high stress) and thus the relationship is not what would be normally expected if birth weight is used as a marker of severity. In contrast, the pattern of correlations between stress and illness perceptions show a strong relationship between more severe perceptions of the baby's illness and the mother's stress level.

Babies in High Dependency Unit

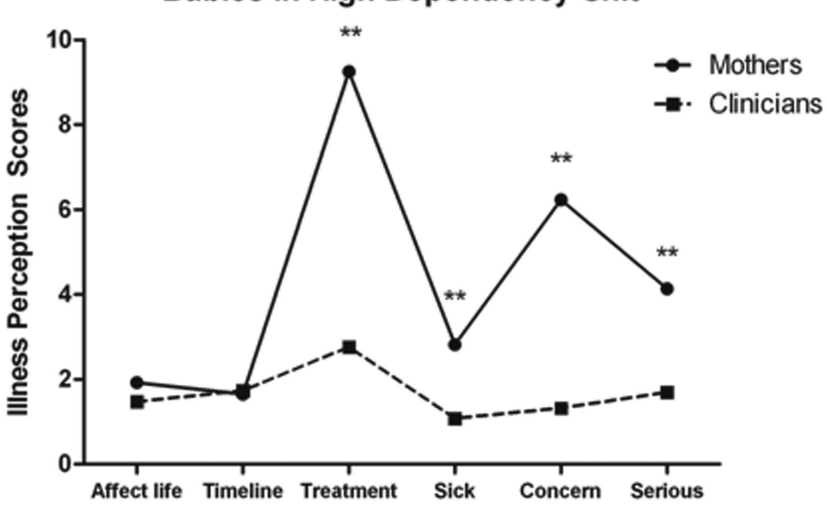

Babies in Intensive Care Unit

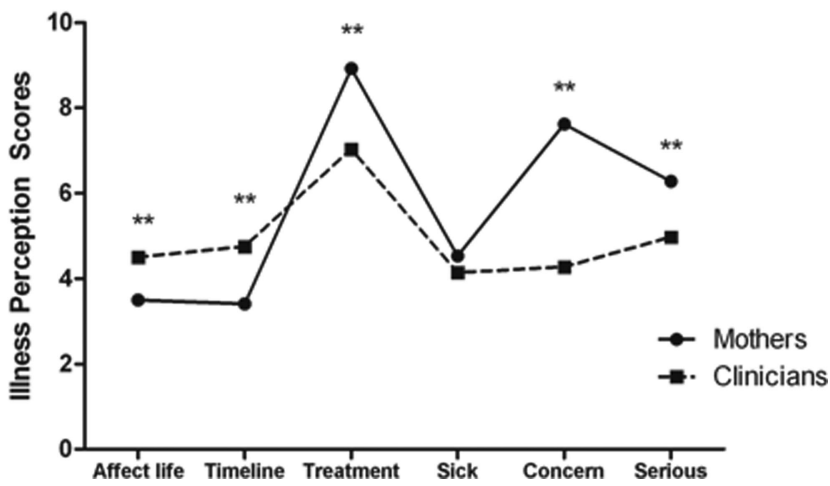

Figure 1. Mean illness perceptions ratings of infants by mothers and clinicians for babies admitted to the high dependency and intensive care units.

\section{Discussion}

This study investigated the correspondence between mothers' and clinicians' perceptions of the same high-risk newborns and how mothers' perceptions were related to objective illness severity and to their current levels of stress. The data showed that mothers' perceptions of the severity of their baby's illness were unrelated to objective measures of illness severity or to clinician ratings of the same infant. Differences between mothers' and clinicians' ratings varied depending on the type of unit. In the high dependency unit mothers consistently perceived their baby's condition as worse than did clinicians. While in the intensive care unit, clinicians rated the baby's illness as affecting his or her life more and also rated the effects of the illness lasting a longer time than did mothers. In both the intensive care and the high dependency unit mothers rated the medical treatment as being more helpful than did clinicians. The reason for the differences between the units may be that babies in the intensive care unit had more severe illness than babies in the high dependency unit, and clinicians were better able to recognize the signs of severe illness and their implications than mothers were.

As expected, mothers of high-risk infants report high levels of stress but the data showed stress to be unrelated to whether their baby was admitted to the high dependency or intensive care unit or to the actual severity of the baby's illness. However, stress was strongly related to a number of illness perceptions mothers held about their baby's condition. The perceptions associated with stress were a longer perceived timeline for the baby's illness, a lower reported understanding of the illness, as well as a perception that the illness was serious and would affect the baby's later life. We found mothers' perceptions of their baby's illness differed from doctors' views and objective measures of severity but were strongly associated with their level of stress.

The relationships seen in this study between mothers' negative perceptions of their baby's illness and stress are consistent with Leventhal's self-regulatory model (Leventhal et al., 1984) which predicts that more severe perceptions of an illness threat cause a concomitant increase in emotion. This relationship has also been shown in a number of recent studies looking at the relationship between patients' illness perceptions and psychological distress 
Table 4

Tests of Differences in Illness Perceptions Between Mothers and Clinicians and Between High Dependency and Intensive Care Units (F Values)

\begin{tabular}{lccrc}
\hline Perception & $d f$ & Unit & Rater & Unit by rater interaction \\
\hline Affect life & 1,92 & $31.15, p<.001$ & $1.03, p=.313$ & $7.15, p=.009$ \\
Timeline & 1,94 & $31.12, p<.001$ & $11.58, p=.001$ & $9.01, p=.003$ \\
Treatment & 1,94 & $37.04, p<.001$ & $99.65, p<.001$ & $60.12, p<.001$ \\
Sick & 1,95 & $42.26, p<.001$ & $14.95, p<.001$ & $6.02, p=.016$ \\
Concern & 1,96 & $24.03, p<.001$ & $126.77, p<.001$ & $4.47, p=.037$ \\
Serious & 1,95 & $31.21, p<.001$ & $38.90, p<.001$ & $3.58, p=.062$ \\
\hline
\end{tabular}

(Chilcot, Wellsted, Davenport, \& Farrington, 2011; Dempster et al., 2011; Jorgensen, Frederiksen, Boesen, Elsass, \& Johansen, 2009).

Perhaps the most interesting aspect of the study is just how different the perceptions of the mothers are from those of the doctors treating the baby and the objective measure of illness severity. Consistent with this finding, an earlier study of parents of babies in a newborn intensive care unit, found no relationship between parents' outcome expectancies and medical measures of illness severity (Affleck et al., 1990). In previous research we have also found that myocardial infarction patients' prediction of their risk of a future heart attack were unrelated to an established clinical risk model but were related to a number of patients' illness perceptions (Broadbent et al., 2006). It is surprising that the correspondence between patients' and doctors' views of the same illness has not received more attention in the research literature. The issue is an important one because often doctors may be unaware of differences between their view and the patient's view of the illness. As it is generally the patient's model of their illness that influences engagement in current treatment and decisions about future treatment options, inaccuracies and systematic biases in illness perceptions can have important health consequences (Petrie \& Weinman, 2012).

There are a number of clinical implications from the results of this study. First, and perhaps most importantly, the differences between parental and neonatologists perceptions of the same baby

Table 5

Correlations Between Mothers' Illness Perception Items and Perceived Stress Score

\begin{tabular}{lc}
\hline \multicolumn{1}{c}{ Variable } & Total stress score \\
\hline Illness perceptions & \\
Illness affect life & $.37^{* *}$ \\
Length illness last & $.35^{* *}$ \\
Control over illness & -.14 \\
Treatment can help & -.17 \\
How sick is baby & $.43^{* *}$ \\
How concerned & $.45^{* *}$ \\
Understand & $-.37^{* *}$ \\
Affect emotionally & $.67^{* *}$ \\
Serious condition & $.38^{* *}$ \\
Severity measures & $.24^{*}$ \\
Birth weight & .19 \\
Gestation & .05 \\
CRIB-II & \\
\hline
\end{tabular}

CRIB-II = Clinical Risk Index for Babies score. provide considerable opportunity for clinicians and parents to "talk past each other" when discussing the care of their baby. These misunderstandings center largely around parental misperception of the severity of the baby's illness, the overvaluing of treatment in both the high dependency and intensive care units and the undervaluing of the effect and length of the illness in babies admitted to the intensive care unit. These misperceptions may lead to differences between parents and clinicians in the evaluation of the benefits of different treatment options and ongoing care.

The results of the study also underline the value of clinicians eliciting parental perceptions of their high-risk baby's illness. It may be that a scale like the Brief Illness Perception Questionnaire can be used routinely to identify the perceptions that parents hold about their baby's condition, so inaccurate beliefs can be recognized and more effectively addressed by staff. In normal practice, neonatologists would tend to assume that stress is higher in parents with babies admitted to the intensive care unit than the high dependency unit and, therefore, spend more time or allocate support services more often to these parents. Our data show that mothers of babies admitted to the high dependency unit have similar levels of stress and concern about their infants when compared with parents of babies in the intensive care unit, in fact, their illness perceptions about their baby are very similar. This highlights the importance of more time and information being given to parents in an effort to reframe more accurate illness perceptions and expectations.

While a strength of the study is that information was collected from mothers and clinicians between 3 and 5 days after admission, thus avoiding the retrospective nature of many previous studies in this area (e.g., Allen et al., 2004; Chatwin \& MacArthur, 1993; Redshaw, 1997), it should be noted that the data is cross-sectional and this limits our ability to disentangle the relationship between illness perceptions and perceived stress. The challenge of acute illnesses or hospital admissions means that this limitation is difficult in practical terms to remedy. However, it should be noted that it may be that illness perceptions lead to increased stress levels but it is also possible that the higher stress levels some mothers experience may cause difficulties in accurately understanding and processing information provided during their baby's admission.

The generalizability of the results may be further limited by the nature of the neonatal unit in which we collected data for the study. The Auckland Unit is a large university teaching hospital service with 900 admissions per year and highly trained and experienced staff, which may limit the applicability findings to other neonatal units. It should also be noted that the generalizability of the findings may be limited by the number of parents who could not be 
reached or declined to participate in the study. This was mainly because as a tertiary referral unit, the hospital frequently transfers infants once they have stabilized, back to other hospitals in the region. This is often within the first few days and before recruitment could be completed.

Evidence from the current study suggests that parents' perceptions of their high-risk infants do not correspond with clinicians' views and are unrelated to objective ratings of severity. Interventions designed to address faulty perceptions may be valuable in terms of reducing the high levels of stress found in mothers in this study and correcting inaccurate perceptions of infant vulnerability. There have now been several randomized controlled trials that have demonstrated improved outcomes based around changing illness perceptions (e.g., Broadbent, Ellis, Thomas, Gamble, \& Petrie, 2009b; Petrie, Perry, Broadbent, \& Weinman, 2011), and this approach may also prove useful in the future in the neonatal hospital setting.

\section{References}

Affleck, G., Tennen, H., \& Rowe, J. (1990). Mothers, fathers, and the crisis of newborn intensive care. Infant Mental Health Journal, 11, 12-25. doi:10.1002/1097-0355(199021)11:1<12::AID-IMHJ2280110103> 3.0.CO;2-P.

Allen, E. C., Manuel, J. C., Legault, C., Naughton, M. J., Pivor, C., \& O'Shea, M. (2004). Perception of child vulnerability among mothers of former premature infants. Pediatrics, 113, 267-273. doi:10.1542/ peds.113.2.267.

Bean, D., Cundy, T., \& Petrie, K. J. (2007). Ethnic differences in illness perceptions, self efficacy and diabetes self care. Psychology \& Health, 22, 787-811. doi:10.1080/14768320600976240.

Broadbent, E., Ellis, C. J., Thomas, J., Gamble, G., \& Petrie, K. J. (2009a). Can an illness perception intervention reduce illness anxiety in spouses of myocardial infarction patients? A randomized trial. Journal of Psychosomatic Research, 67, 11-15. doi:10.1016/j.jpsychores.2008.11.006.

Broadbent, E., Ellis, C. J., Thomas, J., Gamble, G., \& Petrie, K. J. (2009b). Further development of an illness perception intervention for myocardial infarction patients: A randomized trial. Journal of Psychosomatic Research, 67, 17-23. doi:10.1016/j.jpsychores.2008.12.001.

Broadbent, E., Petrie, K. J., Ellis, C. J., Ying, J., \& Gamble, G. (2004). A picture of health - myocardial infarction patients' drawings of their hearts and subsequent disability: A longitudinal study. Journal of Psychosomatic Research, 57, 583-587. doi:10.1016/j.jpsychores .2004.03.014.

Broadbent, E., Petrie, K. J., Main, J., \& Weinman, J. (2006). The Brief Illness Perception Questionnaire. Journal of Psychosomatic Research, 60, 631-637. doi:10.1016/j.jpsychores.2005.10.020.

Broadbent, E. Petrie, K. J., Ellis, C. J., Anderson, J. Gamble, G., Anderson, D., \& Benjamin, W. (2006). Acute myocardial infarction patients have an inaccurate understanding of their risk of a future cardiac event. Internal Medicine Journal, 36, 643-647. doi:10.1111/j.14455994.2006.01150.x.

Catlett, A. T., Miles, M. S., \& Holditch-Davis, D. (1994). Maternal perceptions of illness severity in premature infants. Neonatal Network, 13, 45-49.

Chatwin, S. L., \& MacArthur, B. A. (1993). Maternal perceptions of the preterm infant. Early Child Development and Care, 87, 69-82. doi: 10.1080/0300443930870107

Chilcot, J., Wellsted, D., Davenport, A., \& Farrington, K. (2011). Illness representations and concurrent depression symptoms in haemodialysis patients. Journal of Health Psychology, doi:10.1177/135910531401672.

Chong, J., Mackey, A., Broadbent, E., \& Stott, N. S. (in press). Children's perceptions of their cerebral palsy contribute to their life satisfaction. Disability and Rehabilitation.

Cohen, S., Kamarck, T., \& Mermelstein, R. (1983). A global measure of perceived stress. Journal of Health and Social Behavior, 24, 385-396. doi: $10.2307 / 2136404$.

Cohen, S., \& Williamson, G. M. (1988). Perceived stress in a probability sample of the United States. In S. Spacapan \& S. Oskamp (Eds.), The social psychology of health (pp. 31-67). Newbury Park, CA: Sage.

Cole, S. R. (1999). Assessment of differential item functioning in the Perceived Stress Scale-10. Journal of Epidemiology and Community Health, 53, 319-320. doi:10.1136/jech.53.5.319.

Dempster, M., McCorry, N. K., Brennan, E., Donnelly, M., Murray, L. J., \& Johnston, B. T. (2011). Illness perceptions among carer-survivor dyads are related to psychological distress among oesophageal cancer survivors. Journal of Psychosomatic Research, 70, 432-439. doi: 10.1016/j.jpsychores.2010.07.007.

Dickens, C., McGowan, L., Percival, C., Tomenson, B., Cotter, L., Heagerty, A., \& Creed, F. (2008). Negative illness perceptions are associated with new-onset depression following myocardial infarction. General Hospital Psychiatry, 30, 414-420. doi:10.1016/j.genhosppsych .2008.04.003.

Foster, N. E., Bishop, A., Thomas, E., Main, C., Horne, R., Weinman, J., \& Hay, E. (2008). Illness perceptions of low back pain patients in primary care: What are they, do they change and are they associated with outcome? Pain, 136, 177-187. doi:10.1016/j.pain.2007.12.007.

Frostholm, L., Fink, P., Christensen, K. S., Toft, T., Oernboel, E., Olesen, F., \& Weinman, J. (2005). The patients' illness perceptions and use of primary health care. Psychosomatic Medicine, 67, 997-1005. doi 10.1097/01.psy.0000189164.85653.bc.

Frostholm, L., Oernboel, E., Christensen, K. S., Toft, T., Olesen, F., Weinman, J., \& Fink, P. (2007). Do illness perceptions predict health outcomes in primary care patients? A 2-year follow-up study. Journal of Psychomatic Research, 62, 129-138. doi:10.1016/j.jpsychores.2006.09.003.

Gagliardi, L., Cavazza, A., Brunelli, A., Battaglioli, M., Merazzi, D., Tandoi, F., Cella ... Bellu, R. (2004). Assessing mortality risk in very low birthweight infants: A comparison of CRIB, CRIB-II, and SNAPPEII. Archives of Disease in Childhood: Fetal and Neonatal Edition, 89, F419-F22. doi:10.1136/adc.2003.031286.

Giri, P., Poole, J., Nightingale, P., \& Robertson, A. (2009). Perceptions of illness and their impact on sickness absence. Occupational Medicine, 59, 550-555. doi:10.1093/occmed/kqp123.

Hobel, C. J. (2004). Stress and preterm birth. Clinical Obstetrics and Gynecology, 47, 856-880. doi:10.1097/01.grf.0000142512.38733.8c.

Janse, A. J., Sinnema, G., Uiterwaal, C. S. P. M., Kimpen, J. L. L., \& Gemke, R. J. B. J. (2008). Quality of life in chronic illness: Children, parents and paediatricians have different, but stable perceptions. Acta Paediatrica, 97, 1118-1124. doi:10.1111/j.1651-2227.2008.00847.x.

Jorgensen, I. L., Frederiksen, K., Boesen, E., Elsass, P., \& Johansen, C. (2009). An exploratory study of associations between illness perceptions and adjustment after psychosocial rehabilitation in survivors of breast caner. Acta Oncologica, 48, 1119-1127. doi:10.3109/02841860903033922.

Kalidindi, S., Mahajan, P., Thomas, R., \& Sethuraman, U. (2010). Parental perceptions of urgency of illness. Pediatric Emergency Care, 26, 549553. doi:10.1097/PEC.0b013e3181ea71b3.

Lantéri-Minet, M., Massiou, H., Nachit-Ouinekh, F., Lucas, C., Pradalier, A., Radat, F., ... El Hasnaoui, A. (2007). The GRIM2005 study of migraine consultation in France I. Determinants of consultation for migraine headache in France. Cephalalgia, 27, 1386-1397. doi:10.1111/ j.1468-2982.2007.01426.x.

Leventhal, H., \& Diefenbach, M. A. (1991). The active side of illness cognition. In J. A. Skelton \& R. T. Croyle (Eds.), Mental representation in health and illness (pp. 247-272). New York: Springer-Verlag. doi: 10.1007/978-1-4613-9074-9_11.

Leventhal, H., Nerenz, D. R., \& Steele, D. J. (1984). Illness representations 
and coping with health threats. In A. Baum, S. E. Taylor, \& J. E. Singer (Eds), Handbook of psychology and health (pp. 219-251). Hillsdale, N. J.: Lawrence Erlbaum Associates.

Mitchell, A. M., Crane, P. A., \& Kim, Y. (2008). Perceived stress in survivors of suicide: Psychometric properties of the Perceived Stress Scale. Research in Nursing \& Health, 31, 576-585. doi:10.1002/nur.20284.

Morrow, A. M., Hayden, A., Quine, S., Scheinberg, A., \& Craig, J. C. (2012). A comparison of doctors', parents' and children's reports of health states and health-related quality of life in children with chronic conditions. Child: Care, Health and Development, doi:10.1111/j.13652214.2011.01240.x

Parry, G., Tucker, J., Tamow-Mordi, W., \& U. K. Neonatal Staffing Study Collaborative Group. (2003). CRIB II: An update of the clinical risk index for babies score. Lancet, 361, 1789-1791. doi:10.1016/S01406736(03)13397-1

Petrie, K. J., Perry, K., Broadbent, E., \& Weinman, J. (2012). A text message program designed to modify patients' illness and treatment beliefs improves self-reported adherence to asthma preventer medication. British Journal of Health Psychology, 17, 74-84. doi:10.1111/j. 2044-8287.2011.02033.x.

Petrie, K. J., Weinman, J., Sharpe, N., \& Buckley, J. (1996). Role of patients' view of their illness in predicting return to work and functioning after myocardial infarction: Longitudinal study. British Medical Journal, 312, 1191-1194. doi:10.1136/bmj.312.7040.1191.

Petrie, K. J., \& Weinman, J. (2006). Why illness perceptions matter. Clinical Medicine, 6, 536-539.

Petrie, K. J., \& Weinman, J. (2012). Patients' perceptions of their illness: The dynamo of volition in health care. Current Directions in Psychological Science, 21, 60-65. doi:10.1177/0963721411429456
Redshaw, M. E. (1997). Mothers of babies requiring special care: Attitudes and experiences. Journal of Reproductive and Infant Psychology, 15, 109-120. doi:10.1080/02646839708404538.

Sanders, D., Kydd, R., Morunga, E., \& Broadbent, E. (2011). Differences in patients' perceptions of schizophrenia between Maori and New Zealand Europeans. Australian and New Zealand Journal of Psychiatry, 45, 483-488. doi:10.3109/00048674.2011.561479.

Shaw, R. J., Deblois, T., Ikuta, L., Ginzburg, K., Fleisher, B., \& Koopman, C. (2006). Acute stress disorder among parents of infants in the neonatal intensive care nursery. Psychosomatics, 47, 206-212. doi:10.1176/ appi.psy.47.3.206

Stack, R. J., Bundy, C., Elliot, R. A., New, J. P., Gibson, J. M., \& Noyce, P. R. (2011). Patient perceptions of treatment and illness when prescribed multiple medicines for co-morbid type 2 diabetes. Diabetes, Metabolic Syndrome and Obesity: Targets and Therapy, 4, 127-135. doi:10.2147/DMSO.S17444.

Thompson, R. J., Oehler, J. M., Catlett, A. T., \& Johndrow, D. A. (1993). Maternal psychological adjustment to the birth of an infant weighing 1,500 grams or less. Infant Behavior and Development, 16, 471-485. doi:10.1016/0163-6383(93)80005-S.

Weinman, J., Petrie, K. J., Sharpe, N., \& Walker, S. (2000). Causal attributions in patients and spouses following a heart attack and subsequent lifestyle changes. British Journal of Health Psychology, 5, 263 273. doi:10.1348/135910700168900.

Received June 21, 2011

Revision received December 19, 2011 Accepted December 27, 2011 